\title{
What an Information System Is, and Why Is It Important to Know This
}

\author{
Ray J. Paul \\ Department of Information Systems and Computing, Brunel University, Uxbridge, United Kingdom
}

\begin{abstract}
There are many different views on what the term Information Systems means. This paper provides a simple explanation of what an Information System is in practice to assist in clarifying the confusion. If this simple explanation were widely understood, then current difficulties with Information Systems development, practical problems with ongoing Information Systems, the applicability of much Information System's research, and a general lack of awareness of the potential for the academic study of Information Systems, could all be improved upon. The description of what a practical Information System turns out to be is given, and the reasons why its major features exist and are important are discussed. Implications arising from the acceptance of this definition are offered.
\end{abstract}

Keywords: information systems, information systems development

\section{Preamble}

This paper describes what an Information System (I.S.) is in practice. This is a bold claim to make about the term 'Information System' since there are many definitions already, which, put together, generally confuse an understanding of what the term means. For example, at the time of writing, Wikipedia offered

"In a general sense, the term information system (IS) refers to a system of people, data records and activities that process the data and information in an organization, and it includes the organization's manual and automated processes."

So an I.S. includes Information Technology (the latter part of the sentence from 'data records...' onwards). But the next and third sentences in the same opening paragraph says

"In a narrow sense, the term information system (or computer-based information system) refers to the specific application software that is used to store data records in a computer system and automates some of the information-processing activities of the organization. Computer-based information systems are in the field of information technology."

So now it appears that Information Systems is a part of Information Technology. In mitigation for Wikipedia, there is a warning box at the top of the first page, which says

"This article is in need of attention from an expert on the subject."

So it is clear that what an Information System is, is not clear. The two words 'information system' are common currency in discussions and publications, but a common understanding does not even vaguely exist. For some it is a unique subject for study, for others it is research into information technology, for others it is just another computer system, and for some it is the system that records stores and retrieves all the information that a host organisation needs to survive. Such a variety of interpretations, whilst seemingly never capable of becoming reduced to just one that is universally accepted, means that our faltering ability to provide the system an organisation needs is severely limited.

This paper argues that an elementary description of what an information system actually is, as it is used in practice, whether wisely or not, can be readily described. This description or definition, because it can be seen to be all embracing and straightforward, can then be used as the basis for describing the variety of aspects of information systems given above. For example, to study information system as a topic could be the business of identifying the various systems inherent in any organisation, and 
matching the dynamic nature of the organisations systems to the ongoing updating of the information system to keep up with organisational change. For those researching into the use of information technology, an information system definition would separate their contribution to an information system's constant evolution; presumably concentrating on using the continuing capability of information technology to accurately and speedily store, record and retrieve information.

Since it is unclear what the meaning of an Information System is, and different meanings have different interpretations for different adherents, how can this paper be so definitive (see first sentence of the main body of the paper above)?

So let us assume that what is about to be described may not be acceptable as the meaning of 'Information System' to those who already have decided upon a definition that is too different to the one in this paper. This in a sense is all just terminology. If we call whatever it is that this paper is describing as an 'Investigative Surrogate' for an Information System, then the shorthand 'I.S.' can be taken to mean either 'Information System' or 'Investigative Surrogate' as the reader so chooses. The argument about what an Information System is now unnecessary since we shall use the short hand I.S. So, now the reader can decide on I.S. either being an Information System or an Investigative Surrogate, and then without loss of generality the argument can now proceed.

\section{An I.S. for Any Organisation}

Any organisation will have a way of recording, manipulating and recalling data/information. It could trivially be just a pencil and paper, but since such systems, if they are interesting, are likely to be complex, or troublesome, then we assume there is a computer system of some level of sophistication and some software that makes it work (operating systems, application packages etc.). This combination would be generally universally accepted as being called Information technology (I.T.), although some might think it broader than that. Taking I.T. to be this combination of hardware and software, which is the delivery mechanism for the I.S., then in order for anything to happen, some action needs to take place to trigger activity in the I.T. This action is usually the human using the I.T. to conduct the affairs of the organisation, sometimes as internal activity, and sometimes with external interactions (with the 'customers' of the organisation, be it patients, the public, military platforms or just business). The combination of the use of the I.T. to run the business alongside the human decisions that are made by the users gives a system that exists at that point in time, which is defined as the I.S. at that point in time.

This latter point is crucial to what this paper means by an I.S., because it underlies the way an organisation should think of its I.S. and hence how it nurtures it; and it explains why there are so many spectacular failures or disappointments in the development of I.S. So an I.S. is not a static system, but it changes with the passage of time; in other words, it is dynamic.

The I.T. contains all the formal rules of the system, plus the data/information values at the point of time being considered. The user remembers the informal rules of the system, which will be being added to with system use, since it is not possible to do business with just the formal rules. This is because it is impossible to find a set of formal rules that covers all possible future situations (this point is argued further below). At any point in time, the set of up-todate data and information stored in the I.T. in combination with the set of ad hoc rules derived by the users over time is the I.S. at that point in time.

\section{An I.S. as a Model}

If this view of looking at I.S. is still not clear, then consider that the I.S. is just a model of the organisation at some level of abstraction, approximation and aggregation. Then, if the organisation is changing (and if it is not, then eventually it will be a dinosaur and meet the equivalent fate), then the model should change with the organisation.

So the model should change in line with the organisation's change, otherwise the I.S. is merely a historical version of the I.S.

Of course, if the model were built to cover all changes in the future, then it could be keeping up with organisational change. After all, the I.S., as has been portrayed in the argument so far, has to have its purpose fulfilled by sometimes using ad hoc decisions by the user(s). Why not capture all the ad hoc rules in advance? A simple example is given next (The Raft of the Medusa) to show why this cannot happen in practice. 


\section{The Raft of the Medusa}

The Raft of the Medusa is a painting hanging in the Louvre, which was painted in 1819 by Géricault. The Louvre has this to say about the painting (Géricault, 1819):

"The Raft of the Medusa - a major work in French 19th-century painting - is generally regarded as an icon of Romanticism. It depicts an event whose human and political aspects greatly interested Géricault: the wreck of a French frigate off the coast of Senegal in 1826, with over 150 soldiers on board. ... .

Géricault drew his inspiration from the account of two survivors of the Medusa - a French Royal Navy frigate that set sail in 1816 to colonize Senegal. It was captained by an officer of the Ancien Régime who had not sailed for over twenty years and who ran the ship aground on a sandbank. Due to the shortage of lifeboats, those who were left behind had to build a raft for 150 souls - a construction that drifted away on a bloody 13-day odyssey that was to save only 10 lives. The disaster of the shipwreck was made worse by the brutality and cannibalism that ensued.

Géricault decided to represent the vain hope of the shipwrecked sailors: the rescue boat is visible on the horizon - but sails away without seeing them.

The whole composition is oriented toward this hope in a rightward ascent culminating in a black figure, the figurehead of the boat. The painting stands as a synthetic view of human life abandoned to its fate."

The Louvre website mentions some debate about the painting, but Julian Barnes undertakes a wider discussion in Chapter 5 of his book (Barnes, 1995). Part 1 of the chapter is a description of the shipwreck and the events surrounding the raft. Part II is a 16 page discussion about the painting, what it depicts and does not depict, how one can interpret what is in the painting, what is missing, and what should not be there. To give some examples:

Quote 1. "Let us start with what he did not paint. He did not paint:

- The Medusa striking the reef;

- The moment when the tow-ropes were cast off and the raft abandoned;

- The mutiny in the night;
- The necessary cannibalism;

- The self-protective mass murder;

- The arrival of the butterfly;

- The survivors up to their waists, or calves, or ankles in water;

- The actual moment of rescue."

Quote 2. "The Medusa was a shipwreck, a news story and a painting; it was also a cause. Bonapartists attacked Monarchists. The behaviour of the frigate's captain illuminated a) the incompetence and corruption of the Royalist Navy; b) the general callousness of the ruling class towards those beneath them."

The Louvre quote above speaks of hope fading. Barnes questions whether this is the only interpretation:

Quote 3. "The ship is on the horizon; the sun is also on the horizon (though unseen). Lighting it up with yellow. Sunrise we deduce, and the ship arriving with the sun, bringing a new day, hope and rescue; the black clouds overhead (very black) will soon disappear. However, what if it were sunset? Dawn and dusk are easily confused. What if it were sunset, with the ship about to vanish like the sun, and the castaways facing hopeless night, as black as the clouds overhead? Puzzled, we might look at the raft's sail to see if the machine was being blown towards or away from its rescuer, and to judge if that baleful cloud is about to be dispelled. ... Then, still undecided, a third possibility occurs; it could be sunrise, yet even so the rescuing vessel is not coming towards the shipwrecked. This would be the plainest rebuff of all from fate: the sun is rising but not for you."

The painting has, amongst other unexpected portrayals, some feature of the people on the raft that Barnes picks up on:

Quote 4. "So go on, let's ask. Why do the survivors look so healthy? ... But why does everyone - even the corpses - look so muscled, so ... healthy? Where are the wounds, the scars, the haggardness, the disease?" Of the 15 men on the raft, 5 of them did not survive their rescue very long. "So why do they look as if they have just come from a body-building class"

The relevance to this discussion of I.S. is as follows. Géricault painted a picture representing the shipwreck. Barnes's first quote shows that he had a lot of choice as to how to represent the story, and the choices are very different. So 
although all viewers had the chance to read the story before seeing the picture, and although at first sight the picture might convey the essence of the story, there are in fact many other plausible pictures that could have found equal favour. So when considering what system to build, what are the alternative structurings of the system that might be equally acceptable, but are very different?

Barnes's second quote shows that even with the best intentions, the politics of the organisation can have a large opinion-based impact on the system about to be built. It is often quoted that user participation in systems development leads to greater system success. There is no evidence for this; Bokhari and Paul (2010) discuss a meta-analysis of 90 papers on this subject, and the conclusion was there is no relationship. And this may be one reason why this may not be so: user participation allows political views to be incorporated into system development and thus allows some users to take advantage.

The third quote is even more unsettling. The painting is a two-dimensional static object that can be viewed by anyone, and the picture seen by the viewers is the same. Only, it is not as the quote shows. If two people cannot agree on what they see when looking at a twodimensional static physical object, what chance is there of them agreeing to some future conceptual object in more than two dimensions and which is dynamic? Now, if two or more people thought they were agreeing with each other, how would they know if this were true or not? This quote shows that users 'cannot know what they want' which makes requirements engineering an oxymoron in these situations.

The fourth quote, which is to do with the artist's interest in physiology at the time he made the painting, shows that the system being developed is open to abuse by the developers who can orientate the development around their pet technical approach at the time of development.

\section{A Simple Definition of I.S. and a Simple Analogy}

Since it is not possible to build an IT system that caters for future changes, then we have to consider the combined effect of all parts of the system when considering aspects of the I.S. at any point in time. Since the explanation of what an I.S. is can seem a bit cumbersome, a short approximate definition is offered which, if translated properly, gets you back to a full understanding. The definition is

\section{An I.S. is I.T. in Use}

The 'In Use' part of the definition can be interpreted as the time dimension, as well as the human dimension since the I.T. is in use when users are using it, and the usage is a function of time.

A close analogy to this understanding of I.S. is that of Gardening. Gardening is an activity that can consume as much time as you are willing to give it. A garden is constantly changing; it's never the same twice. To try and determine exactly what you want a garden to look like is pointless because it never stands still. It will have some basic architecture:

- Some paths,

- Some lawn space,

- Some flower beds,

- Some vegetable/fruit patches,

- Some trees.

In the short term these will be fixed, as would some of the basic components and software for the I.T. This architecture would represent the current overview of the organisation's activities. Note that all the above gardening structures are changeable, but any change would be a major effort, maybe suitable to a project approach. Similarly, the creation of the basic architecture might also suit a project approach.

But within the basic architecture, constant change is taking place and has to be dealt with. Paths (communications) need maintaining, else they will break up. Lawns need cutting, as does the build up of wasted storage in the I.T. system. Flower beds, and vegetable patches are very personal, the choice of what to put in and to remove being a matter of personal taste - as with the ad hoc rules for running the system as needs change. The formal structures must not be allowed to outgrow their environment, as with tree growth which can overwhelm a garden. No gardener is ever satisfied with the garden, there is always a mixture of trivial, debugging, and remedial and structural changes to plan and carry out, always planning for the future garden.

And so on. Unless a garden is dealt with in this way, it will grow wild and only be interesting from an environmentally friendly perspective - although the neighbours might not be too 
pleased. A wild I.T. system is often what organisations get, but they do not appear to find them endearing.

So an I.S. is constantly evolving, formal rules are frequently updated as some ad hoc decisions are repeated often enough to make them worth formalising, and some formal rules may be obsolete or even wrong, or contradictory with new rules. Major organisational changes will require matching I.S. changes.

\section{Implications}

You cannot build an I.S. You can build an I.T. system, but remembering to leave enough flexibility for frequent small changes, with a flexible enough architecture to allow major changes periodically as they are needed. The latter might be project-based, but not in the Requirements Engineering level of detail currently being used, rather at a more basic structures level. Small changes need a dedicated team of gardeners, or a combination of application software and user literacy so as to allow the user to tailor the system as they use it.

There is a major ongoing decision as to how much of the business you formalise in the I.T., which provides fast and accurate processing, and how much you trust the users whose strength is adaptability, flexibility and problem solving. Not enough trust in the users will restrain them from running the organisation effectively, and too much of the decision making in the hands of users could make them too slow, and make understanding what is going on difficult.

It follows then that I.S. in practice needs many skills to be made effective; Computer scientist and Software Engineers for the I.T.; HCI and psychology for the users; specialists who understand the organisation well enough to be able to call in experts from any appropriate discipline to help with the I.S. This should be the role of an I.S. specialist, multi-disciplinary and with a systems approach.

Academic research in I.S. scarcely touches the major issues raised above, that is even when it is on those rare occasions addressing real problems. Research should be practice-focussed, not focussing on theory since at the moment our ignorance is not worth theorising about.

\section{Conclusions}

This paper offers a clear simple explanation of what an I.S. is in practice. Whether I.S. stands for Information Systems or Investigative Surrogate should now appear to be less controversial. Information Systems is an appropriate term for what this paper covers. The alternative is to think of another label in which case a lot of rebadging will be necessary. But in either event, an I.S. is just what this paper shows it to be.

The definition of I.S. given here

\section{An I.S. is I.T. in Use}

can be ignored - and if so, then we shall continue with the same poor success rate with I.S. that we currently have.

\section{References}

[1] J. BARNES, A history of the world in 101/2 chapters. Cambridge University Press, 1995.

[2] R. BOKHARI, R. J. PAUL, User participation does not guarantee to improve the chance of system success. In preparation, 2010.

[3] TH. GÉRICAULT, The raft of the Medusa. Use Google to search on 'Medusa Géricault Louvre' and go to the Louvre site, 1819.

Received: June, 2009 Accepted: April, 2010

Contact address: Ray J. Paul Department of Information Systems and Computing Brunel University, Uxbridge Middlesex UB8 3PH, U.K. e-mail: ray.paul@brunel.ac.uk

RaY J. PAUL, Emeritus Professor at Brunel University and Visiting Professor at the London School of Economics, both in the U.K., first attended ITI in 1988. He more or less fell instantly in love with Cavtat, the conference and another conference delegate. Since 1988 Ray has attended well over half the conferences to date, including some when ITI was held in Pula. Ray has also been a member of CIT's Editorial Board since it started, and this will be the fourth or fifth CIT special issue that Ray will have edited. 
